\title{
Increasing productive capacity in block caving mines
}

\author{
KJ Shelswell Labrecque Technologies Inc., Canada \\ PO Labrecque Labrecque Technologies Inc., Canada \\ DM Morrison Centre for Excellence in Mining Innovation, Canada
}

\begin{abstract}
The block caving method requires the effective management of the induced stress conditions and the ore production system. We believe that the primary focus should be on the strategic design of the ore production system that will facilitate the management of the development activities involved in expanding the production footprint. A discrete event simulation was designed to quantify the impact of drawpoint loading methodologies on the productive capacity of block caving extraction footprints. The analysis of a conventional load-haul-dump (LHD) batch production process means it is very difficult for a $300 \mathrm{~m}$ wide footprint to reliably achieve a target of 100,000 tpd. It is always possible to increase the number of active extraction drives and the number of LHDs but this also increases the production cost and creates logistical problems. The analysis also shows that mine production rates much greater than 100,000 tpd can only be achieved by a continuous production system. This approach concentrates production within a smaller area with the potential for steeper caving angles. Higher production rates also shorten the life of drawpoints and reduce the risk of drawpoint failure. We believe the transition from a batch production system to a continuous production system will reduce the cost of production of current block caving operations and is essential if block caving operations are to reliably achieve production rates that are much higher than today.
\end{abstract}

Keywords: discrete event simulation, block caving productivity, continuous production system

\section{Introduction}

Block caving provides a cost-effective alternative to extract low-grade underground operations by applying mass mining methods across large mineral deposits (Laubscher 1994) under the appropriate conditions. The caving of the material is propagated by gravity, the natural geological stresses of the rock mass, and the blasting-induced stresses of the cave initiation once the undercut is developed (Srikant 2006). The high capital expenditure of footprint development is offset by the lower cost of cave extraction when compared to traditional drill-and-blast techniques (Hamrin 1980).

Conventional extraction methods limit the productivity of block caving by implementing equipment such as load-haul-dump units (LHDs) that operate in a batched process (Rashidi-Nejad et al. 2014). This batched extraction necessitates the operation and maintenance of an extensive network of drawpoints to reliably achieve rates that justify the lateral development required to sustain productivity (Rahal et al. 2003). The significant amount of development needed to bring enough drawpoints online requires a long lead time before steady-state production can be reached, and keeping many drawpoints open over extended periods of time present both logistical and maintenance challenges.

The Centre for Excellence in Mining Innovation (CEMI) has approached the challenges of block caving from an extraction perspective, by focusing on a system that targets the inefficiencies of the current batched extraction processes (Atkinson 1992). The result of this initiative is the Mascot (mobile autonomous segmented coarse ore transfer) System designed for the continuous material transfer of base metal ores. The Mascot System comprises three distinct production units each designed to meet the needs of the complex geometries typical of underground mining and mass mining operations. The Mascot System criteria involved designing mobile units that operate in the drifts while allowing equipment to access drawpoints to extract ore and deal with secondary breaking without interrupting the transfer of ore. With the completion 
of the basic designs, CEMI and its partners are currently engaged in negotiations with several manufacturing partners to build the first prototypes for field trials in 2019.

The conception and design of this system has highlighted several opportunities that can be exploited by using a continuous production system (CPS) for block caving operations. A discrete event simulation model (Law \& Kelton 1991) was created to emulate the performance of a typical LHD-based operation and the continuous extraction system under similar operational conditions. The model was used to quantitatively compare the productivity of both approaches and to identify opportunities for improvement. In addition to offering significant improvements to productivity, the application of a continuous loader and mobile conveyance system can permit operations to reach steady-state targets with less development and construction. This reduces the lead time and capital expenditure of the caving process by concentrating production into a smaller area, assuming the hydraulic radius required to sustain continuous caving is met. Furthermore, operating in a smaller area requires the maintenance of fewer open drawpoints, which allows for a steeper caving angle and shorter drawpoint life while extracting the same amount. Finally, the design of the continuous production system also provides an opportunity to decrease construction requirements for roadway conditions.

\section{$2 \quad$ Methodology}

\subsection{Model boundaries}

The upstream boundary used for the study was the extraction of ore from drawpoints. It was assumed that mining activities could efficiently meet the undercutting and lateral development rates to sustain the caving process for the extraction level production targets. The downstream boundary of the simulation was the dumping of material into an orepass system. Orepass capacity was unconstrained so downstream ore re-handling was not included in the simulation.

\subsection{Mine design}

The model was designed to simulate a block cave extraction operation with a $300 \mathrm{~m}$ wide footprint with $4.5 \mathrm{~m}$ wide extraction drives running between the $5 \mathrm{~m}$ wide north and south perimeter drives. Additional access drives were included along the east and west perimeters of the footprint. Extraction drives were $310 \mathrm{~m}$ long, with a drive spacing of $30 \mathrm{~m}$. The footprint was developed in an El Teniente pattern with 36 drawpoints per drive at a $15 \mathrm{~m}$ spacing interval. The load point for the drawpoints was located $8.5 \mathrm{~m}$ in from the extraction drive. The footprint was designed to simulate multiple orepass configurations, with tip points along the footprint perimeter or along the central axis of each drive. The tip point for the perimeter orepasses was $10 \mathrm{~m}$ out from the perimeter drive, while the tip point along the centre axis was located $2.3 \mathrm{~m}$ out from the extraction drive. The equipment maintenance workshop was located off the west end of the southern perimeter drive (Figure 1).

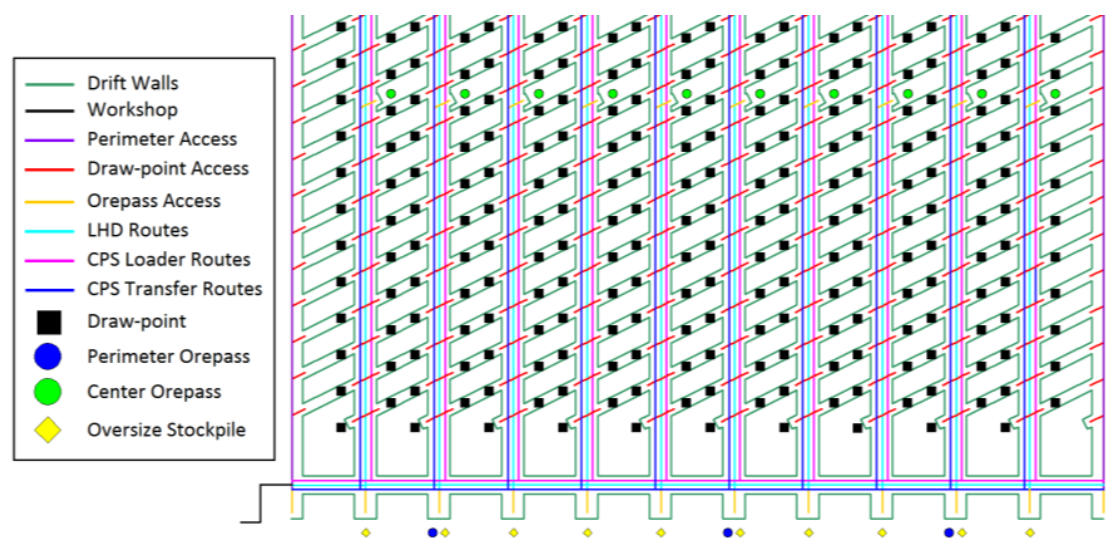

Figure 1 Extraction footprint layout and design. Representative section of the southern portion of the footprint presented. The northern portion of the design mirrors the southern layout from the perimeter to the central orepass 


\subsection{Production scheduling}

The conceptual production schedule represented the mine targets for one calendar year (365 days) at steady-state production. Non-production days representing statutory holidays, maintenance events, and random shutdowns were not included. Scheduling was broken down by drawpoint for each active drive, with production tonnes scheduled daily, based on a maximum height of draw of $300 \mathrm{~mm}$ (Kurniawan \& Setyoko 2008; Nezhadshahmohammad et al. 2017; Rahal \& Smith 2004), to ensure proper draw control, and limit caving problems. Ore tonnes were scheduled additively such that new daily calls of ore tonnes were added to any previously scheduled tonnes not yet extracted from the drawpoints.

\subsection{Shift schedules}

Extraction, secondary breaking, and maintenance activities were modelled as schedule-based resources such that each component of the mining operation could only carry out one process at a time (Karnon et al. 2012). This included extraction LHDs, components of the continuous production system, mobile rockbreakers, drawpoint hang-up crews, and maintenance personnel. These activities were limited to the available hours defined by the appropriate daily shift schedules. Separate schedules were defined for LHDs, the continuous production system equipment, secondary breaking operations, and equipment maintenance.

Shift availability was modelled based on operating two shifts per day for both extraction LHDs and the continuous production system. Shift profiles included an off-shift component consisting of shift changeover, and pre-shift and post-shift factors like safety meetings, line-ups, travel, equipment checks, blasts, and ventilation clearances to generate on-shift periods during which processes could occur. These factors resulted in on-shift workable availabilities of $83.3 \%$ for all equipment to standardise the seat time for the simulation comparisons. This shift availability was comparable to an average workable availability of $81.9 \%$ derived from available industry benchmarking of currently operating block cave mines.

\subsection{Equipment routing and traffic}

Equipment was routed around the footprint based on the orepass configuration simulated. Equipment accessed drives only from the south perimeter for scenarios modelled with only south perimeter orepasses. When the model was run with orepasses along both perimeters (north and south) or along the centre axis of the drive, then equipment moving to drawpoints 1 through 18 accessed the drive from the south perimeter while drawpoints 19 through 36 were accessed through the north perimeter. Equipment transitions between the north and south perimeter was routed along either the east or west access drives.

Traffic interactions between extraction and secondary breaking equipment were explicitly modelled during movement along the perimeter drives. Passing was limited to intersections between the perimeter and extraction drives where equipment could move out of the way of oncoming traffic.

\subsection{Drawpoint extraction}

The extraction operation was modelled using manually operated diesel LHDs or remotely operated diesel continuous production system equipment. Inputs for batched LHD operations were generated based on benchmarking data collected from industry operations utilising eight yard loaders while prototype design specifications were used to derive the continuous production system inputs. Equipment was dispatched to extract ore from drawpoints along the extraction drives to orepasses linking the extraction level with a material re-handling level (haulage or conveyance). Considerations were made in the model programming to include random variability, equipment interactions, and resource competition on the productivity of the extraction process. Inputs used for the extraction equipment are summarised in Table 1, with the modelling process described in Sections 2.6.1 through 2.6.5. 
Table 1 Model inputs used for drawpoint extraction operations

\begin{tabular}{llll}
\hline Input specifications & LHDs & $\begin{array}{l}\text { Continuous } \\
\text { production } \\
\text { loader }\end{array}$ & $\begin{array}{l}\text { Continuous } \\
\text { production } \\
\text { material transfer }\end{array}$ \\
\hline Payload - ore & $12 \mathrm{t}$ & $\mathrm{N} / \mathrm{A}$ & $\mathrm{N} / \mathrm{A}$ \\
Rate - ore & $\mathrm{N} / \mathrm{A}$ & $800 \mathrm{tph}$ & $1,000 \mathrm{tph}$ \\
Load spot - duration & $5 \mathrm{secs}$ & $6.5 \mathrm{secs}$ & $\mathrm{N} / \mathrm{A}$ \\
Load ore - duration & $30 \mathrm{secs}$ & $\mathrm{N} / \mathrm{A}$ & $\mathrm{N} / \mathrm{A}$ \\
Dump spot - duration & 4 secs & $\mathrm{N} / \mathrm{A}$ & $\mathrm{N} / \mathrm{A}$ \\
Dump - duration & $20 \mathrm{secs}$ & $\mathrm{N} / \mathrm{A}$ & $\mathrm{N} / \mathrm{A}$ \\
Setup - duration & $\mathrm{N} / \mathrm{A}$ & $3.5 \mathrm{mins}$ & $\mathrm{N} / \mathrm{A}$ \\
Teardown - duration & $\mathrm{N} / \mathrm{A}$ & $1.5 \mathrm{mins}$ & $\mathrm{N} / \mathrm{A}$ \\
Speed - loaded & $10^{\mathrm{a}}$ or $8^{\mathrm{b}} \mathrm{km} / \mathrm{hr}$ & $\mathrm{N} / \mathrm{A}$ & $\mathrm{N} / \mathrm{A}$ \\
Speed - empty & $11^{\mathrm{a}}$ or $9^{\mathrm{b}} \mathrm{km} / \mathrm{hr}$ & $4 \mathrm{~km} / \mathrm{hr}$ & $4 \mathrm{~km} / \mathrm{hr}$ \\
Break oversize - duration & $\mathrm{N} / \mathrm{A}$ & $3 \mathrm{mins}$ & $\mathrm{N} / \mathrm{A}$ \\
Scheduled maintenance-associated & $95.4 \%$ & $95.4 \%$ & $\mathrm{~N} / \mathrm{A}^{\mathrm{c}}$ \\
availability & & $96.0 \%$ & $\mathrm{~N} / \mathrm{A}$ \\
Pit stop-associated availability & $96.0 \%$ & $97.3 \%$ & $\mathrm{~N} / \mathrm{A}$ \\
Refuelling-associated availability & $97.3 \%$ & $86.5 \%$ & $99.5 \%$ \\
Random failure-associated availability & $86.5 \%$ & $77.1 \%$ & $99.5 \%$ \\
Overall mechanical availability & $77.1 \%$ & &
\end{tabular}

Note: a Average tram speeds of LHDs operating in a $300 \mathrm{~m}$ long drive. ${ }^{\mathrm{b}}$ Average tram speeds of LHDs operating in a $150 \mathrm{~m}$ long drive. ${ }^{\mathrm{c}}$ Assume units are cycled with spares for planned maintenance

\subsubsection{Extraction drive and drawpoint dispatch}

Extraction drives were broken down into work zones based on the orepass configuration simulated for the footprint design. The entire drive was designated as a work zone in scenarios with orepasses only along the south perimeter, while each drive was divided into two work zones for the footprint design scenarios with orepasses located along both the north and south perimeter or along the central axis of the drive.

Only one LHD was dispatched to operate in a work zone at any given time, while up to two continuous production loaders were permitted to operate in the same work zone. Equipment was dispatched to the farthest available drawpoint in the zone and progressively worked toward the orepass; from north to south in the scenarios with only south perimeter orepasses, from the middle of the drive outwards with both north and south perimeter passes, and from the perimeter to the middle of the drive with orepasses along the central drive axis. Drawpoints were designated as available if tonnes were scheduled to be extracted from that location, the drawpoint was not blocked or hung-up, and no drawpoints between the current drawpoint and the orepass had a blockage or hang-up. LHDs were permitted to operate from drawpoints on either side of the drive. However, continuous production loaders were limited to operating along a single side of the drive due to the El Teniente drawpoint access layout before switching sides. 


\subsubsection{Load-haul-dump extraction}

LHDs travelled through the footprint following the routing and traffic rules described in Section 2.5. LHDs trammed to the drawpoint access and spotted in front of the ore before digging in and loading the bucket. Loaded LHDs then exited the drawpoint access and trammed to dump at the designated orepass. If the orepass tip site was free, LHDs proceeded to spot and dump at the pass. If the dump site was occupied by another unit, LHDs queued to wait for access to the pass tip site. The duration of the drawpoint spotting, loading, orepass spotting, and dumping processes was modelled using a triangular distribution with a $\pm 8 \%$, $\pm 20 \%, \pm 9 \%$, and $\pm 25 \%$ variability, respectively (Forbes et al. 2011 ).

LHDs continued to operate at each location until the maximum consecutive number of trips was made to the drawpoint, the scheduled daily tonnes were extracted, or the unit encountered a blockage or hang-up. Oversize encountered by the LHDs was moved to a stockpile location at the head of the drive along the perimeter before LHDs could continue extracting from the drawpoint. If no more drawpoints were available in the work zone, the equipment was dispatched to another available zone. If no other zones were available, the LHD was parked near the workshop until another work area became available.

\subsubsection{Continuous production system extraction}

The continuous production loaders travelled through the footprint following the routing and traffic rules described in Section 2.5. Continuous production loaders moved to the drawpoint access before spotting in front of the ore and setting up. Once set up, the loaders proceeded to extract ore from the drawpoint onto the transfer component of the system. The equipment spotting and setup processes were modelled using a triangular distribution with a $\pm 8 \%$ and $\pm 20 \%$ variability, respectively (Forbes et al. 2011).

The system extracted ore from the drawpoint and transferred the material as discrete single tonne entities (Robinson 2004) in a non-accumulating process (Rockwell Automation 2014) where ore could only enter the system if there was an available space large enough and not already occupied by another tonne of ore. Each tonne was transferred progressively between units of the system from the drawpoint to the orepass. The flow of ore along the system was regulated by the capacity and ability of each unit in the system. Ore flow was halted if there was not sufficient space to transfer tonnes between units or if the downstream unit was stopped due to a random failure.

The continuous production loader unit operated at each location until the maximum consecutive tonnes of ore was extracted from the drawpoint, the scheduled daily tonnes were extracted, or the unit encountered a blockage or hang-up. Oversize in the drawpoint was broken using a rockbreaker mounted on the loader unit, with the duration of breaking oversize modelled using a triangular distribution with a $\pm 35 \%$ variability (Forbes et al. 2011). Units leaving a drawpoint incurred a teardown delay with a $\pm 10 \%$ variability before moving to another drawpoint. If no more drawpoints were available in the work zone, the equipment was dispatched to another available zone. If no other zones were available, the continuous production loader was parked near the workshop until another work area became available.

\subsubsection{Secondary breaking}

Fragmentation in the model was simulated to include oversize and drawpoint blockages/hang-ups (Dirkx et al. 2018). The model generated oversize and hang-ups as ore was extracted from each drawpoint by using a fragmentation profile for each extraction drive. The average secondary breaking frequencies were modelled at $227 \mathrm{t}$ per oversize, and 4,452 t per blockage/hang-up. The occurrence of blockages and hang-ups generally decreases as the height of draw increases, so an average value from benchmarking data of steady-state operations was used for the blockage/hang-up frequency. The probability of encountering problematic fragmentation was simulated by sampling the ratio of the average LHD bucket capacity or the maximum extraction rate of the continuous production system to the fragmentation frequency. Secondary breaking inputs are summarised in Table 2. 
Table 2 Model inputs used for secondary breaking operations

\begin{tabular}{lll}
\hline Input specifications & Rockbreakers & Hang-up rigs \\
\hline Number of units & 3 & 3 \\
Break oversize - duration & 7 mins & N/A \\
Free blockage - duration & $\mathrm{N} / \mathrm{A}$ & $30 \mathrm{mins}$ \\
Initial success rate - probability & $\mathrm{N} / \mathrm{A}$ & $75 \%$ \\
Free hang-up - duration & $\mathrm{N} / \mathrm{A}$ & $90 \mathrm{mins}$ \\
Tramming speed & $6 \mathrm{~km} / \mathrm{hr}$ & $6 \mathrm{~km} / \mathrm{hr}$ \\
\hline
\end{tabular}

Mobile rockbreakers were used to break oversize in scenarios with LHD-simulated operations, but not during the continuous production system scenarios as the loader equipment was designed to incorporate a rockpick. Mobile rockbreakers were dispatched to oversize stockpiles on the perimeter as required following the routing and traffic rules described in Section 2.5. Only one unit was dispatched per stockpile, with the equipment remaining until all pieces at that location were broken. The duration of breaking oversize was modelled using a triangular distribution with a $\pm 35 \%$ variability (Forbes et al. 2011).

Hang-up rigs were used to either free blockages or drill and load hang-ups in the drawpoints. Hang-up rigs travelled through the footprint following the routing and traffic rules described in Section 2.5. Only one rig was dispatched to a drawpoint at a given time, although multiple rigs could operate concurrently at different drawpoints in the same drive. Hang-up rigs initially attempted to free the ore using a non-explosive blockage approach, with the success rate determined by the initial success rate input. If the non-explosive approach failed, rigs proceeded to use drill-and-blast technology to resolve difficult hang-ups. The duration of the hang-up resolution process was based on triangular distributions using a $\mathrm{min} / \mathrm{mode} / \mathrm{max}$ function for freeing blockages and drilling hang-ups (Forbes et al. 2011). Mode values were used instead of mean or median values to avoid predisposing the functions to a uniform distribution. Hang-up rigs were dispatched to the drawpoint farthest from the orepass requiring blockage/hang-up resolution, before proceeding to the next available drawpoint blockage/hang-up in the drive, progressing toward the orepass until all hang-ups in the drive were resolved or prepared for blasting. Hang-up blasts and venting of fumes were carried out during the underground shift change period.

\subsubsection{Equipment availability}

Equipment availability was modelled on the extraction equipment to include downtime associated with planned maintenance regimes, pit stops, random equipment failures, and refuelling. All maintenance was completed at the workshop location, while refuelling was carried out by a mobile fuel/lube truck. The workshop maintenance was modelled as a resource with the capacity to work on three pieces of equipment at a time, and the operation was supplied with a single fuel/lube truck.

Discretely modelled variables tracking individual equipment utilisation were used to schedule planned maintenance and random failure events (Robinson 2004). Industry maintenance routines were used to model the recurring interval used for planned maintenance using a distribution of $\pm 20 \%$ on the duration of maintenance to represent the service process. Random failures were modelled using a triangular distribution (Forbes et al. 2011) sampling a min/mode/max function (Onyango \& Plews 1987) generated from mean time between failure (MTBF) and mean time to repair (MTTR) benchmarking data from industry and projected for the continuous production loader equipment. Mode values were used to avoid limiting the distribution of the functions as described in Section 2.6.4. Equipment refuelling and pit stops were staggered to prevent unnecessary queueing by using a uniform distribution (Forbes et al. 2011) to schedule the service during each shift, also with a $\pm 20 \%$ distribution on the duration of the events. 
Planned maintenance on the transfer components of the continuous production system was modelled under the assumption that units were swapped out of service regularly, with a sufficient fleet size to allow operations to continue without interruption. Random failures were modelled as described above using an MTBF distribution which calculated the overall availability of a set of units operating in series between extraction drive intersections; sets were determined based on equipment length and drawpoint spacing. Random failures were resolved by replacing the failed equipment with a functional unit, with the duration of the replacement modelled by sampling a triangular distribution of a $\mathrm{min} / \mathrm{mode} / \mathrm{max}$ mean time to replace. Mode values were used to avoid limiting the distribution of the functions as described in Section 2.6.4. Five crews dedicated to maintenance swap-outs on the transfer components were modelled for the simulation.

Planned maintenance and random failures on the mobile rockbreakers and hang-up resolution equipment was not simulated under the assumption that enough equipment was available to meet the secondary breaking rate of the caving process.

\section{Data and results}

The model was used to quantify the productivity of a 10-drive panel extracting toward three orepasses along the south perimeter. This was chosen as the base case because moving the dump points off the footprint minimises the risk associated with orepass construction and maintenance, and reduces the development cost by localising the downstream material handling along a single perimeter shared by each drive. The base case was then compared to scenarios with orepasses along both perimeters or in each drive to quantify the benefits of alternate design configurations on the extraction process. The discrete simulation was used to track the activity of each piece of equipment in the process, as well as the performance of each drawpoint, to create performance profiles for the comparison of extraction with LHDs versus the continuous production system.

\subsection{Batched load-haul-dump extraction}

The model was used to characterise the productivity of block caving operations using conventional methods. LHDs were used to simulate batched extraction operations loading at the drawpoint, tramming ore to an orepass, and returning to load again from the drawpoint. Initial simulations compared the performance of the LHDs using inputs derived from data gathered by industry benchmarking (see Section 2). A secondary analysis was carried out to quantify the impact of doubling the speed of LHDs, under the assumption that roadway conditions, drive maintenance, and collision avoidance protocols were adequately improved to allow for the increase in tram speeds. LHD productivity results are summarised in Table 3.

Table 3 Model results generated for LHD extraction operations

\begin{tabular}{llll}
\hline $\begin{array}{l}\text { LHD } \\
\text { operations }\end{array}$ & $\begin{array}{l}\text { South perimeter } \\
\text { orepasses }\end{array}$ & $\begin{array}{l}\text { North and south } \\
\text { perimeter orepasses }\end{array}$ & $\begin{array}{l}\text { Centre of drive } \\
\text { orepasses }\end{array}$ \\
\hline 1× speed & $30,732 \mathrm{tpd}$ & $35,763 \mathrm{tpd}$ & $48,896 \mathrm{tpd}$ \\
$2 \times$ speed & $46,160 \mathrm{tpd}$ & $52,217 \mathrm{tpd}$ & $66,147 \mathrm{tpd}$ \\
\hline
\end{tabular}

Simulation results predicted that a fleet of 10 LHDs can extract an average of 30,732 tpd from 10 active drives with three orepasses located along the south perimeter. Daily variability was generated by equipment availability and secondary breaking activities, which produced fluctuations in daily productivity from a low of around $22,900 \mathrm{tpd}(-25.5 \%)$ to a high of approximately $35,400 \mathrm{tpd}(+15.2 \%)$.

Increasing development by adding three orepasses along the north perimeter and splitting each drive into two work zones increased the LHD productivity by $16.4 \%$, which was attributed to decreasing the average tram distance by half and reducing queueing to dump at the orepasses. Maintaining two work zones per drive and moving the passes into the footprint along the central axis of each drive resulted in an increase in productivity of $59.1 \%$. This was attributed not only to the shorter average tram distance, but also to eliminating perimeter traffic interactions from the cycle and minimising orepass dump queueing. 
Increasing the LHD tram speeds improved productivity by $50.2,46$, and $35.3 \%$ for the south perimeter, north and south perimeter, and drive centre orepass configurations, respectively. Increasing tram speeds generated shorter cycle times. However, the benefit was partially mitigated by an increase of approximately $64 \%$ in delays associated with queueing for the orepass dump sites.

\subsection{Continuous production system extraction}

The LHD operations were then compared against the productivity of the CPS designed by CEMI to contrast the productivity of batched methodologies against those with a continuous flow. The initial simulations maintained a similar operating procedure which allowed only one continuous production system loader unit to operate per drive, with the transfer components moving ore to three orepasses located along the south perimeter drive. The analysis of the continuous production system was then expanded to permit up to two loader units to operate together and to split each drive into two work zones with orepasses along both the north and south perimeters. Continuous production system results are summarised in Table 4.

Table 4 Model results generated for continuous production system extraction operations

\begin{tabular}{lll}
\hline CPS operations & South perimeter orepasses & North and south perimeter orepasses \\
\hline $1 \times$ loaders per work zone & 53,185 tpd & 56,511 tpd \\
$2 \times$ loaders per work zone & 49,635 tpd & 55,033 tpd \\
\hline
\end{tabular}

Ten continuous production system units extracting from 10 active drives to three orepasses located along the south perimeter averaged around 53,200 tpd. Similar to LHDs, daily variability was attributed to equipment availability and secondary breaking constraints with a minimum productivity of roughly $32,800 \mathrm{tpd}(-38.4 \%)$ and a maximum throughput of approximately $69,000 \mathrm{tpd}(+29.9 \%)$.

The transfer components of the continuous production system were designed with a higher capacity to allow up to two loader units to operate in unison with one series of transfer components (Table 1). The intention was to maximise the flow rate while both loader units were working and maintain a continuous flow of material while one unit moved between drawpoints. The decrease in productivity observed when up to two continuous production loader units were permitted to operate together ( 9.5\%) indicated that the benefit of operating an additional drive outweighed the contribution of maximising a single drive; sustaining an additional $200 \mathrm{tph}$ to maximise one drive came at the expense of operating an additional available drive at $800 \mathrm{tph}$. It was beneficial to try to keep the loader units working alone in different drives instead of combining them in one drive and decreasing the productivity of the second unit by 600 tph to maximise the capacity of the material transfer components.

Expanding the development to split drives into two work zones with orepasses along both the north and south perimeters only increased productivity by approximately $8.6 \%$. This was because the continuous production system negates the impact of transfer distance that constrained the LHD-based batched process. Instead, the increase in productivity was associated with the availability of the mobile transfer components of the system. The shorter transfer length coupled with splitting the drives into two work zones translated to fewer units operating in series, which equated to an overall higher availability of the stream (Shelswell \& Labrecque 2014). Analysis of the activity profile for the continuous production system indicated that $18.4 \%$ of total loader unit operations were lost to downtime on the transfer components of the system. This indicated that the availability of the transfer components was a very sensitive input and a key component of the overall Mascot System process. The dependency of the system on the availability of the transfer components was highlighted by increasing the probability of failure on each mobile unit by $0.5 \%$. This marginal change in availability decreased the maximum productivity of the continuous production system from around 67,500 to 41,500 tpd with one loader unit per drive operating toward orepasses on the south perimeter. It also required that the number of dedicated swap-out crews be doubled from five to 10 to approach the maximum extraction productivity and sustain a rate of approximately 39,000 tpd. 


\subsection{Comparison of batched and continuous production system extraction}

The base case used for comparison of LHD versus continuous production system extraction was a fleet of 10 loader units operating in 10 drives with three orepasses located along the south perimeter drive. The batched approach yielded an equipment productivity of around 3,000 tpd per LHD, whereas the continuous method generated approximately 5,300 tpd per continuous production loader unit - an increase of $\sim 73 \%$. This was attributed to the inefficiency of batched material handling; for every tonne of ore moved to the orepass, an LHD had to move $3 \mathrm{t}$ of machine both to and from the drawpoint. The LHDs spent around $45.1 \%$ of the time moving, whereas the continuous production system loaders moved only about $3.2 \%$ of the time. LHD movements consisted of tramming from the drawpoints to the orepasses and reallocations between drawpoints while the movement of the continuous production system loaders only entailed reallocations between drawpoints. As a result, only approximately $9.4 \%$ of the LHD activity involved extracting from the drawpoint while roughly $33 \%$ of the continuous production system loader operation consisted of extracting ore from the drawpoint. The percentage of time equipment was actively extracting ore from the drawpoints is summarised in Figure 2.

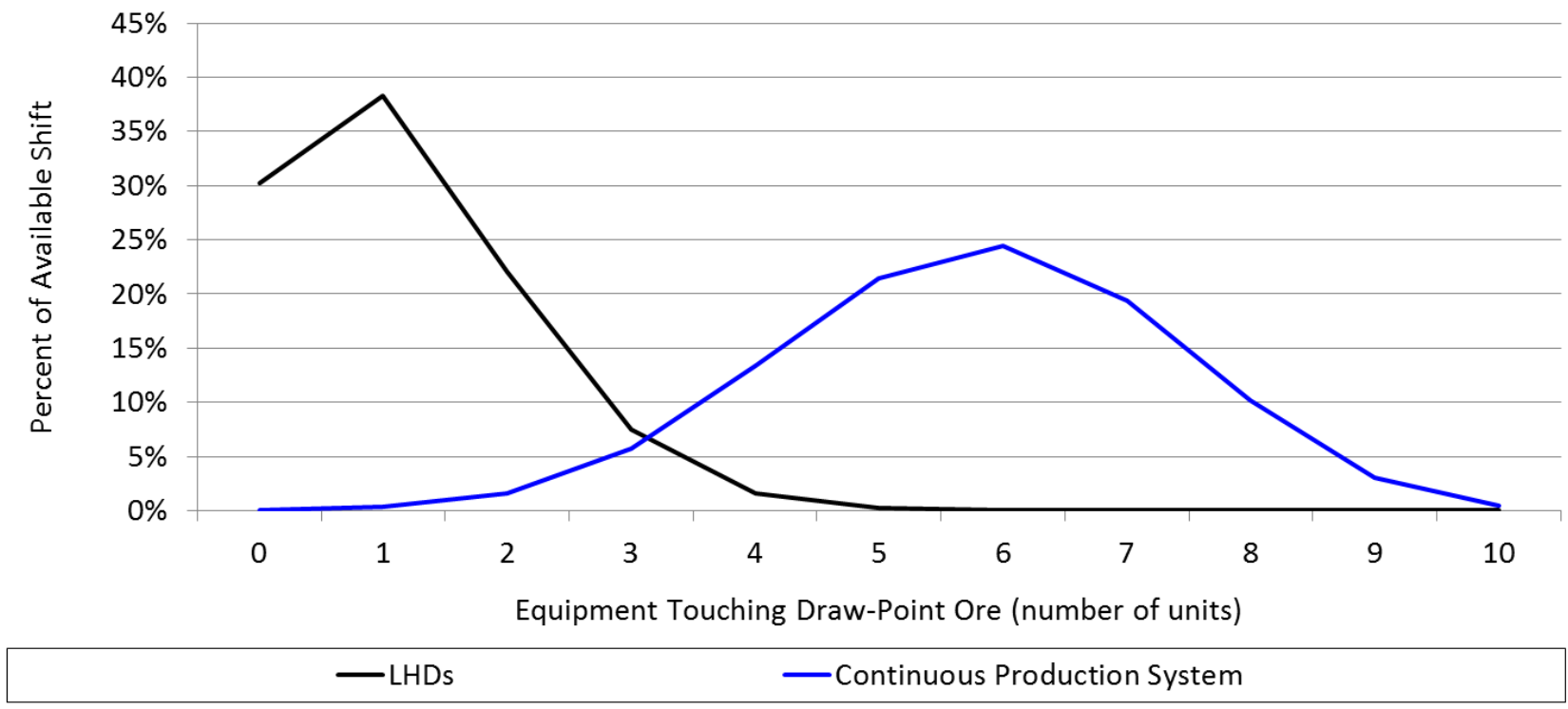

Figure 2 Percentage of time equipment was touching any drawpoint ore in 10 available drives with 10 LHDs or 10 continuous production loaders

The equipment fleet was then expanded to quantify the maximum productivity that could be achieved from 360 drawpoints operating out of 10 drives. The base case scenario with three orepasses along the south perimeter was compared against breaking each drive into two work zones by adding three orepasses along the north perimeter for scenario two or by using 10 orepasses located along the central axis of each drive for scenario three. The productivity of LHDs operating at $1 \times$ speed (see Section 3.1 ) was compared against the continuous production system with $99.5 \%$ availability on the mobile transfer components (see Section 3.2).

The base case LHD scenario reached a maximum of approximately $40,000 \mathrm{tpd}$, whereas the continuous production system was capable of around $70,000 \mathrm{tpd}$. Developing orepasses along both the north and south perimeter allowed the LHD extraction to match the continuous production system extracting only to the south perimeter. Establishing orepasses in the centre of each drive significantly boosted productivity to roughly $90,000 \mathrm{tpd}$. However, it was unable to match the productivity of the continuous production system extracting to passes along both the north and south perimeter which was shown to be capable of exceeding 100,000 tpd (Figure 3). 


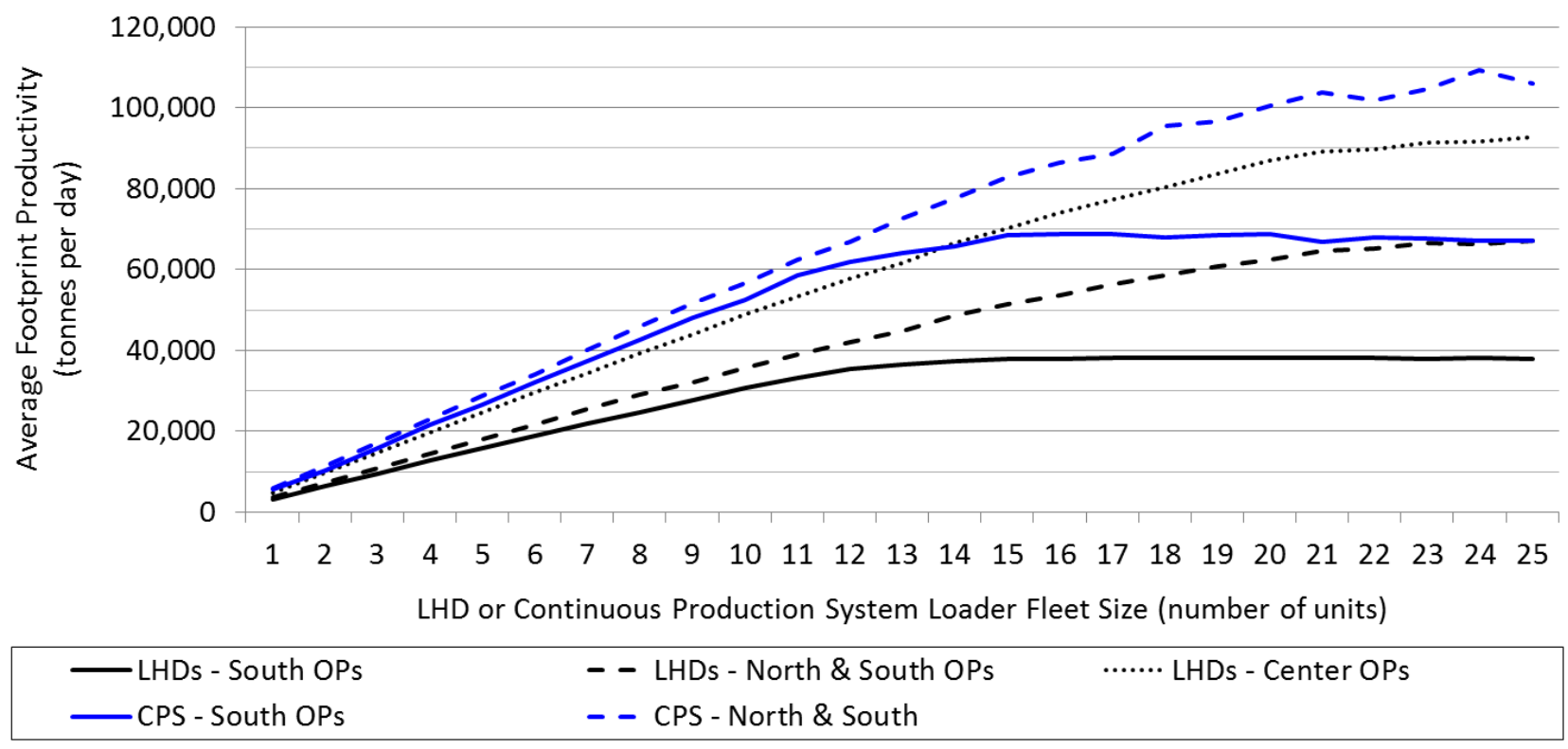

Figure 3 Extraction level productivity based on orepass configuration and fleet size operating in 10 available drives

The goal of this study was to conceive and design a system that would allow the block cave extraction process to reliably reach productivity targets of 100,000 tpd or higher. Of the three orepass configuration scenarios, the CPS offered the most benefit over LHDs in the base case configuration with three orepasses located along the south perimeter. This was because scenario two required twice the pass development to add orepasses along the north perimeter, while the third scenario increased the amount of development 3.3-fold by constructing orepasses along the centre of each drive. Establishing passes off the perimeter also significantly reduces the geotechnical risk associated with constructing and maintaining the orepasses along the centre of drives within the less-stable rock mass of the footprint. Extrapolation of the base case simulation data indicated that a continuous production system operating with orepasses along a single perimeter could produce 100,000 tpd from 19 active drives and six perimeter orepasses, whereas batched LHD extraction methods would require 33 active drives and 10 perimeter orepasses to sustain a rate of 100,000 tpd. Localising the ore transfer along a single perimeter with fewer orepasses further reduces the management of geotechnical conditions required to establish the infrastructure needed for the downstream ore transfer process. The projected equipment and development requirements needed to sustain an extraction rate of 100,000 tpd are summarised in Table 5.

Table 5 Model results extrapolated to achieve 100,000 tpd operations

\begin{tabular}{llll}
\hline Extraction operations & Extraction units & Active drives & Available drawpoints \\
\hline CPS - south orepasses & 19 & 19 & 677 \\
LHDs - south orepasses & 33 & 33 & 1,172 \\
LHDs - north and south orepasses & 28 & 28 & 1,007 \\
LHDs - centre orepasses & 21 & 21 & 737 \\
\hline
\end{tabular}

The continuous production system was predicted to be capable of achieving 100,000 tpd with fewer active drives than the LHD method. This would be expected to reduce the initial demand for lateral development and construction, permitting a block cave operation to ramp-up to full steady-state production more rapidly. Furthermore, the reduction in the number of drawpoints required to sustain the production rate should reduce the maintenance and risk associated with keeping drawpoints open. Extracting the same quantity of ore over a shorter period could reduce the exposure of active drawpoints to stress factors, other than wear 
and tear, that can cause drawpoint failures. The increased productivity of the continuous production system provides the ability to achieve target rates with fewer open drawpoints than with LHDs (Figure 3 and Table 5) which translates to an opportunity to work the cave two ways. The continuous production system can operate within a smaller active work area with the same number of drives with the same caving angle. Alternatively, the cave can be operated within a smaller active work area from fewer drives and, if the geotechnical constraints allow for, a steeper caving angle (Figure 4).

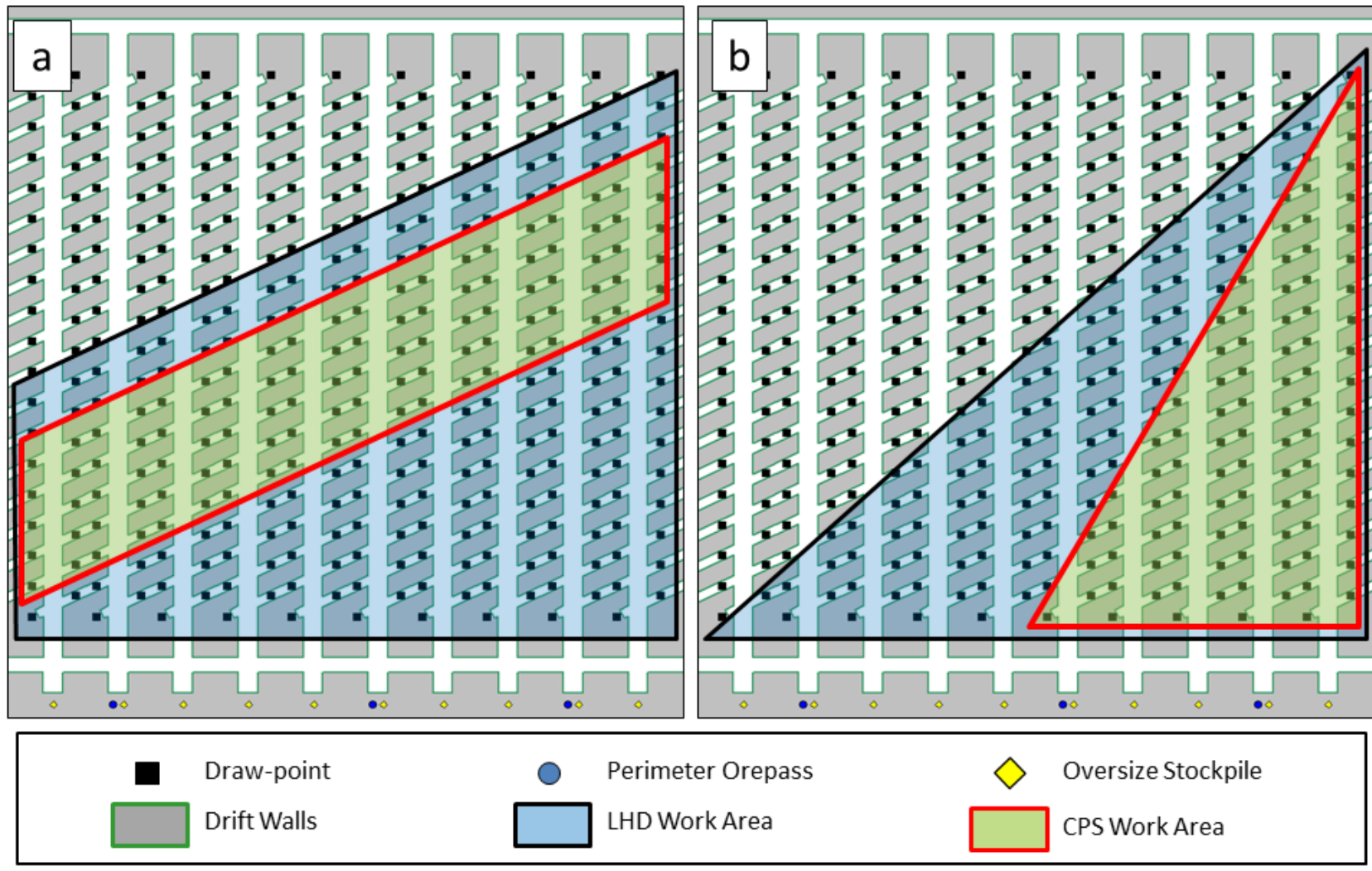

Figure 4 Comparison of work areas for batched LHD extraction and continuous production system extraction. (a) LHD versus CPS work areas with the same number of drives and caving angle; and, (b) LHD versus CPS work areas with a different number of drives and different caving angles

\section{Conclusion}

Continuous ore transfer systems are common in mines extracting sedimentary deposits, but they are uncommon in hard rock metal mines. It is difficult to design continuous systems that can cope with all the operational variables, such as the density and size distribution of metal ores and the complex geometries typical of metal mines. The current transition in mobile equipment design from diesel-powered vehicles to battery electric vehicles will mitigate some of the ventilation constraints deep in mines and will likely meet the needs of relatively small-tonne precious metal mines. However, batched operations are challenged to meet the future demands of deep underground deposits or mines required to produce more than 3,000 tpd.

The ore transfer rate is one of the key hurdles encountered when designing the production system for mass mining operations exceeding 50,000 tpd. Our simulation has highlighted several limitations to batched LHD extraction methods that constrain the productivity of block caving operations below 100,000 tpd. The model results have shown how a continuous production system can circumvent several of these restrictions to increase material transfer rates beyond 100,000 tpd for an underground block caving footprint mine. The Mascot System conceived at CEMI offers the opportunity to generate higher productivities from a smaller extraction area. This leads to a decreased lag time during the ramp-up period, allows orepasses to be kept outside of the mine footprint, and decreases the amount of time drawpoints must be kept open. 
Finally, the transition from batched operations to continuous systems is expected to be gradual. LHDs are better at dealing with oversize material in the early stages of a drawpoint lifecycle, while continuous systems cope best as the caving proceeds and the flow of material from the drawpoint improves. A practical view combines the use of conventional and novel methods such that the extraction method transitions synergistically from a batched to a continuous system as the caving process advances and matures.

\section{References}

Atkinson, T 1992, 'Selection and sizing of excavating equipment', in HL Hartman (ed.), SME Mining Engineering Handbook, Volume 2 , 2nd edn, Society for Mining, Metallurgy, and Exploration, Englewood, pp. 1311-1333.

Dirkx, R, Kazakidis, V \& Dimitrakopoulos, R 2018, 'Stochastic optimisation of long-term block cave scheduling with hang-up and grade uncertainty', International Journal of Mining, Reclamation and Environment, https://dx.doi.org/10.1080/ 17480930.2018.1432009

Forbes, C, Evans, M, Hastings, N \& Peacock, B 2011, Statistical Distributions, John Wiley \& Sons, Hoboken.

Hamrin, H 1980, Guide to Underground Mining Methods and Applications, Atlas Copco, Stockholm.

Karnon, J, Stahl, J, Brennan, A, Caro, JJ, Mar, J \& Möller, J 2012, 'Modeling using discrete event simulation: a report of the ISPOR-SMDM Modeling Good Research Practices Task Force-4' Value In Health, vol. 15, no. 6, pp. 821-827.

Kurniawan, C \& Setyoko, TB 2008, 'Impact of rock type variability on production rates and scheduling at the DOZ-ESZ block cave mine', in H Schunnesson \& E Nordlund (eds), Proceedings of MassMin 2008, Luleå, pp. 291-301.

Laubscher, DH 1994, 'Cave mining - the state of the art', Journal of the South African Institute of Mining and Metallurgy, vol. 94 , no. 10 , pp. $279-293$.

Law, AM \& Kelton, WD 1991, Simulation Modelling and Analysis, 2nd edn, McGraw-Hill Inc., New York.

Nezhadshahmohammad, F, Khodayari, F \& Pourrahimian, Y 2017, 'Draw rate optimisation in block cave production scheduling using mathematical programming', in M Hudyma \& Y Potvin (eds), Proceedings of the First International Conference on Underground Mining Technology, Australian Centre for Geomechanics, Perth, pp. 309-322.

Onyango, JP \& Plews, AM 1987, A Textbook of Basic Statistics, East African Educational Publishers Ltd., Nairobi.

Rahal, D, Smith, M, van Hout, G \& von Johannides, A 2003, 'The use of mixed integer linear programming for long-term scheduling in block caving mines', in FA Camisani-Calzolari (ed.), Proceedings of the 31st Symposium on Application of Computers and Operations Research in the Minerals Industries, South African Institute of Mining and Metallurgy, Johannesburg, pp. 123-132.

Rahal, D \& Smith, M 2004, 'A draw control system for scheduling production in block caving', in A Karzulovic \& MA Alfaro (eds), Proceedings of MassMin 2004, Instituto de Ingenieros de Chile, Santiago, pp. 479-485.

Rashidi-Nejad, F, Suorineni, FT \& Asi, B 2014, 'Open pit or block caving? A numerical ranking method for selection', Proceedings of the 2014 Society of Mining Professors Annual Meeting, The Southern African Institute of Mining and Metallurgy, Johannesburg, pp. 183-199.

Robinson, S 2004, Simulation: The Practice of Model Development and Use, John Wiley \& Sons, West Sussex.

Rockwell Automation 2014, Arena User's Guide, Rockwell Software Inc., Milwaukee.

Shelswell, KJ \& Labrecque, PO 2014, 'Discrete simulations quantifying the effects of material handling conveyors in series or parallel oreflow streams', Proceedings of the Society for Mining, Metallurgy \& Exploration Annual Meeting, Society for Mining, Metallurgy \& Exploration, Englewood.

Srikant, A 2006, 'Fragment size estimation and measurement in the DOZ block cave', Mining Engineering, vol. 58, no. 10, pp. $43-47$. 